\title{
Preserving 3D
}

\section{Data Types Series}

Artefactual Systems and the Digital Preservation Coalition

\section{DPC Technology Watch} Guidance Note July 2021 


\section{The Data Type Guidance Note Series}

Each Guidance Note in the Data Types series is designed to provide a primer on the current state of community knowledge about data types commonly encountered by those seeking to preserve digital holdings. Digital preservation is about keeping information findable, usable, and trustworthy over the long-term. The best approach for any repository will vary according to the scope and content of its holdings, available resources, and the expectations of its funders and users. There are however, broadly applicable good practices that have been established as a result of many years of research, practical implementation, and consensus building. These are presented here as a starting point, along with additional resources for further exploration.

This series of Data Type Guidance Notes has been authored by staff at Artefactual Systems in collaboration with the Digital Preservation Coalition. These notes have been developed in conjunction with the UK Nuclear Decommissioning Authority.

Digital preservation is an evolving field and continues to change and develop in response to external drivers and fresh challenges. New formats, standards, and examples of good practice will emerge over time and the information contained within this report will need to be updated. We welcome comments and feedback to: info@dpconline.org. 


\section{Overview of data type}

3D file formats contain data that represent three-dimensional space and embedded information needed to render this data. 3D formats encompass a wide range of potential applications spanning many fields of research and implementation. They include:

- Cultural heritage data, such as digital representations of scanned museum artefacts.

- Point cloud captures (sets of data points in three-dimensional space) of buildings, archaeological sites, and historical structures.

- Surface models and scenes created for visual effects, video games, and animation.

- Models for 3D printed objects.

- Virtual Reality (VR) and Augmented Reality (AR) files or systems.

- Digital artworks.

Below are some basic terms used when talking about 3D data.

- Mesh, or wireframe model, is a term used to describe the collection of vertices, edges, and faces that define the shape of a polyhedral object (Wikipedia, 2021a).

- Orthorectification is the process of removing perspective (camera tilt) and terrain (relief) information from an image (OSSIM, 2014). Aerial photography and satellite imagery introduce these distortions due to earth curvature, topographical changes, and sensor view point, but orthorectification corrects them (Setyawan, 2019) and is used during the photogrammetry process of going from 2D images to 3D models.

- Point Clouds are sets of data representing locations in physical space. The data points have $X, Y$, and $Z$ coordinates and are thus able to represent 3D objects.

- Skeletons are the hierarchical connected bone structure used as a framework for overlaying and animating the surface representation, or mesh. It is used in skeletal animation (Wikipedia, 2021c).

- Skinning is the process of attaching the mesh to the skeleton (CLIR, 2019, p.70).

- Voxels are basic elements of volume (often cubic) in a 3 dimensional array, a 3D equivalent of a pixel (CS3DP, 2020a).

For information on the 3D CAD (Computer Aided Design) data type, please see the Guidance Note on CAD (Artefactual \& DPC, 2021).

\section{Preservation challenges}

There are many challenges in preserving 3D data. As well as the complexity of the data itself, there is a lack of interoperability between the different (often proprietary) systems that are used to create and manipulate 3D models. Relationships to other data, software and hardware also need to be captured and managed effectively.

\subsection{Complexity}

3D objects can be highly complex, often consisting of multiple source files created by proprietary software and hardware. Mashal Ahmad and Kathryn Cassidy argue that efforts to preserve 3D data are 'further complicated by the fact that in order to replicate the exact scene or model we often need to preserve a lot of additional metadata related to devices, scanners, tools and equipment used to capture the data.' (Ahmad and Cassidy, 2020, para. 6). 


\subsection{Lack of interoperability}

There are innumerable 3D hardware and software platforms in use, as well as different data formats and standards. Some of the common platforms include:

- $\quad$ After Effects, Blender (.blend).

- Cinema 4D (.c4d).

- Lightwave (.Iwo).

- Faro Scene (.cpe, .e57, .vrml, .dxf, .iges, .fls, .pts, .ptx, .pod).

- 3ds Max (.max).

- Maya (.ma, .mb).

- Revit (.rfa, .rvt).

- Rhinoceros 3D (.3dm).

- Skanect, Sketchup (.skp).

- Unreal Engine and Unity (games).

- V-Ray (architectural rendering).

Many of these offerings are proprietary, which limits their interoperability with different technical environments. In the case of digital artworks, proprietary software, custom software, and specific versions of hardware can make updating the artworks for exhibit challenging. The University of Cambridge Centre for Digital Built Britain produced a report in 2020 calling for the development of open 3D model formats in order to increase operability, along with greater standardization and better educational opportunities for preservers.

\subsection{External dependencies}

3D software systems or processes can be self-contained or linked to external resources.

Dependencies may include URIs that are not stable, or references to other software or systems that are necessary for accessing the material in the future. Examples of these kinds of external resources are GIS, game engines (e.g. Unity, Unreal Engine), or hardware such as VR headsets. Information about dependencies can be a necessary precondition to providing access to a 3D model, and can support future format migrations and emulation access strategies.

\subsection{Cultural and ownership issues}

Cultural organizations, particularly museums, often hold artefacts with complicated histories relating to their acquisition and use. In recent decades this has led to initiatives to repatriate artefacts to the communities that originally created or owned them. In such cases, creating 3D laser scans of the artefacts is a means to ensure that museum patrons and the general public can continue to have access to the artefacts. However, the desire and ability to make these digital surrogates broadly available may also conflict with indigenous principles and protocols surrounding the viewing and use of the artefacts (Christen and Pugh, 2011, p. 190).

\section{File formats}

There is no single perfect format for the preservation and future use of 3D data. Decisions made on file formats should be dependent on the features and functionality to be preserved and the future use cases to be supported. The table below lists vendor-neutral or open formats compatible with multiple software systems. These open formats can be considered acceptable preservation formats for different 3D use cases. Compatibility with multiple software systems also makes these file formats potential access formats. 
Be aware that consensus on preservation formats for 3D data has not been reached. For example, the Library of Congress does not list any 3D formats as 'preferred' preservation formats. Note that the most suitable format for preserving the important features and functionality of a file may be the original format that it was created in. It is recommended that careful research and analysis is carried out before migrating files to a new format.

For further information about file formats, Marxent Labs provides a thorough overview of the latest and most popular 3D formats, including an extensive list of current formats, in Essential guide to 3D

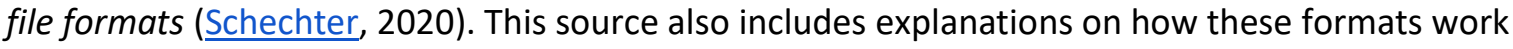
and information about other 3D fundamentals.

\begin{tabular}{|c|c|c|}
\hline File format & Extensions & Brief summary \\
\hline $\begin{array}{l}\text { ASTM E57 } \\
\text { 3D file } \\
\text { format, } \\
\text { Version } 1.0\end{array}$ &.$e 57$ & $\begin{array}{l}\text { E57 is a non-proprietary format with a published specification ( } \underline{\text { ASTM }} \text {, } \\
2019) \text { used as a storage format for point clouds, as well as for images and } \\
\text { metadata produced by laser scanners and other 3D imaging systems. E57 is } \\
\text { partially XML-based and can be extended to support new hardware or } \\
\text { software environments (libE57, 2009). The Open Heritage 3D portal, which } \\
\text { is managed by an international consortium of partners and contributors, } \\
\text { provides online access to 3D objects in E57 format (Open Heritage 3D, } \\
\text { 2019). }\end{array}$ \\
\hline COLLADA & dae & $\begin{array}{l}\text { COLLADA (COLLAborative Design Activity), also referred to as DAE, is an } \\
\text { XML-based 3D file format used in interactive applications (e.g. animation } \\
\text { and game engines) (CLIR, 2019, p. 126). This open format is standardized } \\
\text { through ISO (ISO, 2019). COLLADA supports some metadata fields, can } \\
\text { contain scale information, and can be read and exported by a number of } \\
\text { 3D applications (CLIR, 2019, p.126). }\end{array}$ \\
\hline $\begin{array}{l}\text { Extensible } \\
\text { 3D (X3D) }\end{array}$ & $\begin{array}{l}. \times 3 d \\
. \times 3 d v \\
. x 3 d b \\
. x 3 d z \\
. x 3 d b z \\
. x 3 d v z\end{array}$ & $\begin{array}{l}\text { Extensible 3D (X3D) is a family of file formats that evolved from the Virtual } \\
\text { Reality Modelling Language (VRML). X3D is developed and maintained by } \\
\text { the Web 3D consortium, which describes it as 'a royalty-free open standard } \\
\text { for publishing, viewing, printing and archiving interactive 3D models on the } \\
\text { Web' (Web 3D Consortium, 2020). X3D files include an associated run-time } \\
\text { architecture for communicating the scenes and objects. The National } \\
\text { Archives and Records Administration (NARA, 2020) and Library of Congress } \\
\text { (LC, 2020-2021) list this as an acceptable preservation format. }\end{array}$ \\
\hline $\begin{array}{l}\text { Hierarchica } \\
\text { I Data } \\
\text { Format }\end{array}$ & $\begin{array}{l}. h d f, . h 4, \\
. h d f 4, \\
. h e 2, . h 5, \\
. h d f 5, \text {,he5 }\end{array}$ & $\begin{array}{l}\text { Hierarchical Data Format family is a series of file formats developed by the } \\
\text { University of Illinois National Center for Supercomputing Applications to } \\
\text { organize and store large sets of data, including 3D datasets. The formats } \\
\text { are supported by a non-profit organization called the HDF Group, which } \\
\text { develops free and open-source tools and libraries to promote their use and } \\
\text { interoperability (HDF Group, 2020). }\end{array}$ \\
\hline
\end{tabular}




\begin{tabular}{|l|l|l|}
\hline $\begin{array}{l}\text { Polygon } \\
\text { File Format }\end{array}$ & .ply & $\begin{array}{l}\text { The Polygon File Format (PLY) was developed by Stanford University in } \\
1994 \text { and has been in use since then. It is sometimes also called the } \\
\text { Stanford Triangle Format, or Stanford PLY. PLY describes objects as } \\
\text { polygonal models or point clouds. Library of Congress' (2020-2021) } \\
\text { Recommended formats statement considers PLY files to be an acceptable } \\
\text { format for scanned 3D objects. }\end{array}$ \\
\hline $\begin{array}{l}\text { STereoLith } \\
\text { ography }\end{array}$ &. stl & $\begin{array}{l}\text { The STereoLithography (STL) file format is used to describe the surface of } \\
\text { an object, with the data representing objects in the form of triangular } \\
\text { meshes. STL is an openly documented proprietary format. Its developer, 3D } \\
\text { Systems, encourages its use in multiple platforms (LC, 2021d). STL is a de } \\
\text { facto industry standard for 3D printing and is widely supported as an } \\
\text { export format in 3D modelling software. Library of Congress (2020-2021) } \\
\text { considers STL files to be an acceptable format for scanned 3D objects. }\end{array}$ \\
\hline $\begin{array}{l}\text { Wavefront } \\
\text { OBJ }\end{array}$ & $\begin{array}{l}\text { obj } \\
\text { OBJ is a file format developed by Wavefront Technologies and used by } \\
\text { multiple 3D technology software applications to represent 3D geometry as } \\
\text { ASCII text (FileFormat.Info, 2020). This is a popular format for storing 3D } \\
\text { mesh data, but it does not support skeletons, skinning, or animation data } \\
\text { (CLIR, 2019, p. 126). This format is used for storage and exchange between } \\
\text { systems. Library of Congress' (2020-2021) Recommended formats } \\
\text { statement considers OBJ files to be an acceptable format for scanned 3D } \\
\text { objects. }\end{array}$ \\
\hline
\end{tabular}

\section{Metadata standards}

- buildm is a standard for descriptive metadata based on Architectural Data Objects (Lindlar, Panitz, and Gadiraju, 2015). This model draws a distinction between the Physical Asset and the Digital Object to disambiguate the many optional fields. The Physical Asset requires latitude and longitude fields, while the Digital Object requires information about the object creator and filename.

- E57m is a technical metadata standard for the e57 file format available through the libE57 reference implementation libraries (Lindlar, et al., 2015). It describes 3D scans and/or 2D images contained in e57 files.

\section{Standards Initiatives}

- Community Standards for 3D data preservation (CS3DP). CS3DP is an inclusive, interdisciplinary community focused on developing practices for digital 3D data preservation (CS3DP, 2020a). This group is open to all and has several working groups on the topics of access, best practices, management, metadata, and rights. More information about CS3DP's work can be found on its wiki (CS3DP, 2019).

- Durable Architectural Knowledge (DURAARK). The EU-funded DURAARK project, launched in 2013, was designed to develop standards and tools for architectural records, with an 
emphasis on using standardized metadata and ingesting 3D models into OAIS-based preservation systems (DURAARK, n.d.; Lindlar and Saemann, 2014). The project has a GitHub organization with repositories for a '[s]ervice-platform for long-time preservation of architectural knowledge, based on e57 (plointcloud) [sic] and IFC files' (GitHub, 2020).

- International Image Interoperability (IIIF). The IIIF community has a working group dedicated to exploring ways to view, search, and annotate 3D objects using the IIIF framework. The group 'provides an opportunity for institutions interested in interoperability to coordinate strategies and facilitate conversations about open standards that support 3D use cases' (IIIF 3D community group, n.d., para. 1).

\section{Tips for creators}

\subsection{Prior to creation}

- Creators should work with records managers or archivists at an early stage in any activity that involves the creation of 3D files. This will make it easier to determine what types of content should be preserved, such as final products, associated working files, working versions of final products, outtakes, or partial renderings such as textures. It will also help determine best practices for documentation, metadata creation and retention that support the goals of long-term preservation and access.

\subsection{Creation of 3D formats}

- Software tools and formats in the 3D modelling domain tend to evolve rapidly. Creators should be encouraged to create or export their data in vendor-neutral, standardized formats whenever possible, to mitigate the risk of format obsolescence.

- Capturing information about the creation process is important, especially when creating content in proprietary or niche formats. This includes information such as the make and model of the scanner, the original creating application and file format, and information about any converters that send data to storage packages (Lindlar, 2020).

- Review and test work after uploading to different experience platforms such as Sketchfab, 3DHop, and Smithsonian Voyager, to ensure that the files can be rendered in different environments.

- If working with external vendors, be careful to ensure that there are no copyright or other intellectual property issues that could constrain preservation of 3D objects.

- For those creating 3D laser scans of architecture and cultural heritage objects, follow best practices and standards set by the cultural heritage community. 3D laser scanning for heritage: advice and guidance on the use of laser scanning in archaeology and architecture (Historic England, 2018) is a useful resource on this topic.

\subsection{Preparing for transfer to archives}

- Manage externally referenced files: prefer relative paths over absolute, and bind external references prior to transferring files to an archival repository when possible.

- Prepare documentation such as video files and screenshots representing the project, and transfer them to the archives along with the 3D objects themselves. 


\section{Tips for archivists}

\subsection{General guidance}

The following resources provide guidance on preserving and providing access to 3D objects:

- For VR and AR technologies, CLIR (2019) has produced a book, 3D/VR in the Academic Library, to support workflows on this topic.

- The Netherlands Institute for Sound and Vision has also produced a report Preserving the emerging: virtual reality and 360-degree video (Cranmer, 2017) that covers issues and potential preservation strategies for VR.

- The US Library of Congress (2018) conference, Born to Be 3D, focused on the digital stewardship of 3D objects. Proceedings are available online.

- CS3DP (2020b) has a dedicated Further Resources page that can guide archivists towards associated principles of 3D object preservation, particularly within the realm of cultural heritage objects.

- Wayne State University (2015) hosts an annotated bibliography on video game preservation.

- The Netherlands Institute for Sound and Vision has released a report on video game preservation, Browsing History: Archiving Video Game Context (Berendse, 2021) that focuses on collecting context and provides a useful workflow for this process.

- DPC Technology Watch Report Preserving 3D Design and Construction Records has a section on donor conversation and donor agreements (Leventhal \& Thompson, forthcoming).

\subsection{Acquisition and appraisal}

- Software preservation and emulation may aid appraisal and long-term access to highly software-dependent 3D formats (Work, 2019).

- Work closely with creators and records managers early in the lifecycle of 3D objects. This will help ensure that the objects are received in vendor-neutral, sustainable formats wherever possible and that metadata and supporting documentation are sufficient to support preservation efforts.

- Clarify and document any legal or cultural constraints on the preservation and dissemination of 3D holdings before committing to preserving 3D objects.

- Lower fidelity representations such as fly throughs, or even video recordings of 3D objects being viewed, can be useful as objects that are easier to preserve and render. Acquiring them can provide additional, alternative approaches to preserving complex originals, albeit at the loss of much functionality.

- Review and test newly-acquired 3D objects on different experience platforms such as

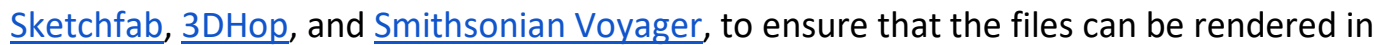
different environments.

\subsection{Characterization}

Characterization can be useful to identify file formats, extract metadata, identify broken or encrypted content, or check conformance to profiles or standards. Tool support and effectiveness can vary considerably for different file formats.

- Identify file formats with a tool such as DROID, FIDO, or Siegfried that uses the PRONOM file format registry. 
- Be aware that not all 3D formats will be identifiable if there are no corresponding entries in PRONOM.

- At this time there are no available validation tools for 3D file formats.

\section{References}

Ahmad, M., and Cassidy, K. (18 September 2020). Experiences Preserving 3D data at the Digital Repository of Ireland. Available at:

https://web.archive.org/web/20201030140804/https://www.dpconline.org/blog/experiencespreserving-3d-data-dri

Artefactual \& DPC (2021) Preserving CAD. Available at: http://doi.org/10.7207/twgn21-15

Berendse, Z. (2021) Browsing History: Archiving Video Game Context. Available at:

https://web.archive.org/web/20210218115722/https://publications.beeldengeluid.nl/pub/1860

buildingSMART (2021) openBIM. Available at:

https://web.archive.org/web/20201121223837/https://www.buildingsmart.org/about/openbim/op enbim-definition/

Centre for Digital Built Britain (2020) BIM Interoperability Expert Group Report. Available at: https://web.archive.org/web/20210129210417/https://www.cdbb.cam.ac.uk/files/cih bim interop erability expert group report april 2020 final wm removed.pdf

Christen, K. and Pugh, M (2011) 'Opening archives: respectful patiration', American Archivist, vol 74, issue 1, p. 190, https://meridian.allenpress.com/american-

archivist/article/74/1/185/24254/Opening-Archives-Respectful-Repatriation [accessed 16 February 2021]

Council on Library and Information Resources [CLIR] (2019) 3D/VR in the Academic Library. Available at:

https://web.archive.org/web/20210129212416/https://projects.iq.harvard.edu/files/buildingtomorr ow/files/3d $\mathrm{vr}$ in the academic library.pdf

Cranmer, C. (2017) Preserving the emerging: virtual reality and 360-degree video, an internship research report. Netherlands Institute for Sound and Vision. Available at:

https://web.archive.org/web/20210218115345/https://publications.beeldengeluid.nl/pub/584

CS3DP (2019) CS3DP (Community Standards for 3D Data Preservation). Available at:

https://web.archive.org/web/20201125053633/https://osf.io/ewt2h/

CS3DP (2020a) CS3DP. Available at:

https://web.archive.org/web/20210129211247/https://cs3dp.org/

CS3DP (2020b) Further Reading. Available at:

https://web.archive.org/web/20201123213518/https://cs3dp.org/further-reading/

GitHub (2020) DURAARK github repository. Available at:

https://web.archive.org/web/20200930001927/https://github.com/DURAARK 
Historic England (2018) 3D laser scanning for heritage: advice and guidance on the use of laser scanning in archaeology and architecture. Available at:

https://web.archive.org/web/20181229142525/https://historicengland.org.uk/images-

books/publications/3d-laser-scanning-heritage/heag155-3d-laser-scanning/

IIIF (2021) IIIF 3D Community Group. Available at:

https://web.archive.org/web/20201218154620/https://iiif.io/community/groups/3d/

ISO (2019) ISO/PAS 17506:2012 Industrial automation systems and integration - COLLADA digital asset schema specification for 3D visualization of industrial data. Available at:

https://web.archive.org/web/20201022132025/https://www.iso.org/standard/59902.html

Leventhal, A and Thompson, J (forthcoming) Preserving 3D Design and Construction Records. DPC Technology Watch Report

Library of Congress [LC] (2018) Born to Be 3D: Digital Stewardship of Intrinsic 3D Data. Available at: https://web.archive.org/web/20201108073039/https://www.loc.gov/preservation/digital/meetings /b2b3d/b2b3d2018.html

Library of Congress (2021a). Industry Foundation Classes (IFC), Clear Text Family. Available at: https://web.archive.org/web/20201024182048/https://www.loc.gov/preservation/digital/formats/f dd/fdd000447.shtml

Library of Congress (2021b) Polygon File Format (PLY) Family. Available at:

https://web.archive.org/web/20201022054616/https://www.loc.gov/preservation/digital/formats/f dd/fdd000501.shtml

Library of Congress (2021c) Reflectance Transformation Imaging (RTI) File Format. Available at: https://web.archive.org/web/20201024153520/https://www.loc.gov/preservation/digital/formats/f dd/fdd000486.shtml

Library of Congress (2021d) STL (STereoLithography) File Format Family. Available at:

https://web.archive.org/web/20201103214753/https://www.loc.gov/preservation/digital/formats/f dd/fdd000504.shtml

Library of Congress (2021e) Extensible 3D (X3D) File Format Family. Available at:

https://web.archive.org/web/20201024001754/https://www.loc.gov/preservation/digital/formats/f dd/fdd000490.shtml

Library of Congress (2020-2021) Recommended Formats Statement: VIII. Design and 3D. Available at: https://web.archive.org/web/20201121155059/https://www.loc.gov/preservation/resources/rfs/de sign3D.html

Lindlar, M. (2020) A practical case study about metadata, Leibniz Information Centre for Science and Technology. Available at:

https://web.archive.org/web/20201009112127/https://www.dpconline.org/docs/miscellaneous/ev ents/2020-events/2269-mickylindlar-metadata-3d/file

Lindlar, M., Panitz, M., and Gadiraju, U. (2015) Ingest and Storage of 3D Objects in a Digital Preservation System. Available at: https://zenodo.org/record/1115512

Lindlar, M. and Saemann, H. (2014) The DURAARK Project-long-term preservation of architectural 3D-Data. Available at: https://doi.org/10.5281/zenodo.1326652 
Moore, F. (Centre for Digital Built Britain) (2020) Information Management, interoperability and the Construction Industry: it's importance and lessons learnt. Available at:

https://web.archive.org/web/20201009111211/https://www.dpconline.org/docs/miscellaneous/ev ents/2020-events/2267-fionamoore-dpc-cdbb-april-2020/file

Open Heritage 3D (2019) How to use the Open Heritage 3D Portal. Available at:

https://web.archive.org/web/20210212181121/https://openheritage3d.org/news.php?p=how-touse-the-open-heritage-portal

OSSIM (2014) Orthorectification. Available at:

https://web.archive.org/web/20201112023028/https://trac.osgeo.org/ossim/wiki/orthorectification

Setyawan, E. (2019) Orthorectification in a Nutshell. Intermap. Available at:

https://web.archive.org/web/20201125073901/https://www.intermap.com/blog/orthorectificationin-a-nutshell

Schechter, S. (2020) Essential Guide to 3D File Formats. Available at:

https://web.archive.org/web/20201027212123/https://www.marxentlabs.com/3d-file-formats/

Wayne State University (2015) Digital Preservation of Video Games. Available at:

https://web.archive.org/web/20210203201204/http://wiki.slis.wayne.edu/index.php/Digital Preser vation of Video Games

Web3D Consortium, About Web3D, 2020. Available at:

https://web.archive.org/web/20201031193052/https://www.web3d.org/about

Wikipedia (2021a) Polygon mesh. Available at:

https://web.archive.org/web/20210119011229/https://en.wikipedia.org/wiki/Polygon mesh

Wikipedia (2021b) Point Cloud. Available at:

https://web.archive.org/web/20201114000255/https://en.wikipedia.org/wiki/Point cloud

Wikipedia (2021c) Skeletal animation. Available at:

https://web.archive.org/web/20210117114701/https://en.wikipedia.org/wiki/Skeletal animation

Work, L. (2019, September 1). FCoP 2020 Cohort Reflections: University of Virginia. Software

Preservation Network. Available at:

https://web.archive.org/web/20210126184535/https://www.softwarepreservationnetwork.org/fco

p-2019-cohort-reflections-university-of-virginia/ 